\title{
Ensinar direito internacional no Brasil: panorama de uma prática \\ e seus desafios ${ }^{* * *}$
}

\section{Teaching International Law in Brazil: A practice overview and its challenges}

RESUMO

Este trabalho expõe os resultados de uma pesquisa exploratória sobre a prática de ensino do direito internacional, pela perspectiva de quem ensina nos cursos de graduação em direito no Brasil. Seu objetivo é jogar luz à diversidade das perspectivas dos docentes entrevistados e, ao mesmo tempo, apontar elementos comuns de fala que os conectam pela similitude de sua prática e de seus desafios. A primeira parte conta quem foram os docentes selecionados na amostra de pesquisa, analisando brevemente seu perfil demográfico e sua formação. A segunda parte traça um quadro geral do ensino da disciplina a partir dos relatos desses docentes, mostrando os aspectos recorrentes dos métodos de ensino adotados e as justificativas dos professores para essas escolhas. A terceira parte enfoca os desafios nas narrativas dos docentes sobre como é ensinar direito internacional no Brasil, que vão desde problemas específicos da disciplina do direito internacional até a falta de infraestrutura em suas instituições.

PALAVRAS-CHAVE

Direito internacional, educação superior, universidade, currículo de ensino, prática docente.

Doutoranda em Teoria e Filosofia do Direito na Universidade de São Paulo (Brasil), com período sanduíche no Erik Castrén Institute of International Law and Human Rights (Universidade de Helsinki, Finlândia). Mestre em Direito Internacional e graduada na Universidade de São Paulo.Contato: adriane.sanctis@gmail.com

Professor de Direito Global da FGv Direito SP (Brasil). Pós-doutor no Instituto Universitário Europeu (Itália), doutor em direito internacional pela Universidade de São Paulo (Brasil), mestre pela Université Pantheón-Assas, Paris 2 (França), graduado em Direito na Pontifícia Universidade Católica de São Paulo (Brasil).Contato: salem.nasser@fgv.br

*** $\quad$ Recibido el 30 de noviembre de 2016, aprobado el 19 de abril de 2017.

Para citar el artículo: SANCTIS de Brito, A. y HiKMAT NASSER, S. Ensinar direito internacional no Brasil: panorama de uma prática e seus desafios. Derecho del Estado n. ${ }^{\circ} 39$, Universidad Externado de Colombia, julio-diciembre de 2017, 119-135. DOI: https://doi.org/10.18601/01229893.n39.06 


\section{ABSTRACT}

This paper presents the results of an exploratory research on international law teaching, from the perspective of those who teach in graduate-level law faculties in Brazil. It aims at shedding light on the diversity of interviewed professors' perspectives and, at the same time, pointing out common elements of speech that connect them by similarity of their practice and challenges. The first part indicates who were the selected teachers of the research sample, briefly analyzing their demographic profile and training. The second part outlines a general framework of how the discipline is taught, based on the professors' accounts, showing aspects of the teaching methods currently adopted and their justifications. The third part addresses the challenges reported in narratives about teaching international law in Brazil, ranging from problems particular to the discipline of international law to the lacking infrastructure in institutions.

\section{KEYWORDS}

International Law, higher education, university, teaching curriculum, teaching practice.

\section{SUMÁRIO}

Introdução. 1. Quem são os professores: perfil demográfico e formação. 2. Perfil do ensino atual: aulas expositivas, interesse dos alunos e conteúdo básico. 3. Os desafios: entre problemas da disciplina e a infraestrutura institucional. Considerações finais. Referências.

\section{INTRODUÇÃO}

São muitos os sinais da importância crescente que o chamado direito internacional, ou aquilo que se vai tendendo a chamar direito global ou direito transnacional, tem adquirido no debate sobre a função social da educação jurídica. Um dos elementos que levam a essa preocupação está ligado ao desempenho profissional dos juristas em um ambiente globalizado. No caso dos países da América Latina, um ponto bastante relevante é o uso instrumental do direito internacional em prol do desenvolvimento ou da melhoria das condições sociais ${ }^{1}$.

1 Ver, especialmente, Unger, R. Magabeira. Uma nova faculdade de direito no Brasil, 2001. Consultado em 13 outubro de $2012 \mathrm{em}$ : www.law.harvard.edu/unger/portuguese/docs/ projetos6.doc Também tocam no tema: BERMAN, S. Towards a Cosmopolitan Vision of Conflict of Laws: Redefining Governmental Interests in a Global Era. University of Pennsylvania Law Review. 2005. V. 153. N. 6, 1819-1882; e SAntos, A. Carving Out Policy Autonomy for 
Mesmo assim, raramente se discute, entre internacionalistas, o que ensinar em uma disciplina de direito internacional ou como ensinar. E, no entanto, esses são problemas enfrentados por professores diariamente, que se veem diante de decisões cruciais em sua prática profissional.

Este artigo apresentará uma imagem, necessariamente geral e panorâmica, de como os professores brasileiros têm feito essas escolhas em seu dia-a-dia ${ }^{2}$. Nossa opção foi por uma investigação exploratória que partiu de reflexões anteriores sobre nossa própria prática de pesquisa e ensino ${ }^{3}$, mas enfocou a realidade da prática de outros profissionais, sobre as quais normalmente não temos qualquer informação sistematizada. Exibiremos aqui alguns resulta-

Developing Countries in the World Trade Organization: The Experience of Brazil. In TRUBeK, D. et al. (eds.). Law and New Developmental State: The Brazilian Experience in Latin American Context. Cambridge: Cabridge University Press, 2013, 167-245.

2 Há um movimento internacional de pesquisas que exploram o aspecto profissional da docência do direito internacional em geral, proveniente de uma preocupação expressada por Oscar Schachter: " $[t]$ he history of the teaching of International law in many countries outside Europe remains to be written". Ver SCHACHTER, O. The Invisible College of International Lawyers, Northwestern Law Review, 1997. V. 72. N. 2, 217-226. Essa preocupação ganha continuidade em locais como o research forum promovido pela European Society of International Law em 2013 (European Society of International Law. International Law as a Profession, 23-15 de maio de 2013. Consultado em 10 de maio de 2016 em: http://www.esil2013.nl/). A discussão aparece também em debates focados no ensino do direito internacional, como nas conferências da International Law Association (ver InTERnational Law Association. Conference Reports, Teaching International Law Committee 1998-2010. Consultado em 10 de maio de 2016 em: http://www.ila-hq.org/en/committees/index.cfm/cid/1009), entre outras iniciativas, como da Société Française pour le Droit International (e.g. Société Française pour le Droit International. Enseignement du Droit International Recherche et Pratique: Journée d'Études du 20 Janvier 1996 Organisée sous les auspices de l'UNESCO. Paris: Pedone, 1997), American Society of International Law (e.g. American Society of International Law. Workshop on the teaching of international law, Washington D.C., 2004). Referências a muitas outras iniciativas acerca do ensino da disciplina podem ser encontradas em: Hoffmann, F. Teaching general public international law. In KAMMERHOFER, J., D’ASPREMONT, J. (eds). International legal positivism in a post-modern world. Cambridge: Cambridge University Press, 2014, 349-377. Nesse artigo, Florian Hoffmann discute os desafios de se ensinar direito internacional na prática, abordados conhecidamente, com outros enfoques, em Simpson, G. On the magic mountain: teaching public international law. European Journal of International Law, 1999. V. 10. N. 1, 70-92; e KenNEDY, D. International Legal Education, Harvard International Law Journal, Cambridge. V. 26, 1985, 361-384. Diante dessas produções, a contribuição desta pesquisa é enfocar a prática brasileira para um registro concreto dos desafios localizados do ensino da disciplina.

3 Ver Hikmat NASSER, S. Imaginação e territoralidade: o ensino do direito internacional. In Ghirardi, J. Garcez. VAnzella, R. D. Faiardo (org.). Ensino jurídico participativo: construção de programas e experiências didáticas. São Paulo: Saraiva, 2009, 129-138; NASSER, S. Hikmat. Uma dança de três: direito internacional, relações internacionais e direito comparado. In BADIN, M. Ratton Sanchez, Brito, A. Sanctis de eVentura, D. de Freitas Lima. Direito global e suas alternativas metodológicas: primeiros passos, São Paulo, Acadêmica Livre, 2016, 169-176; e Brito, A. Sanctis de e KlafKe, G. Forma. O ensino de direito global entre o velho aluno e o novo professor. Ibíd., 177-205. Ver também GHIRARDI, J. GARCEZ. O instante do encontro: questões fundamentais para o ensino jurídico. São Paulo: Fundação Getulio Vargas, 2012. 
dos de nossa pesquisa ${ }^{4}$, que buscou traçar um primeiro perfil do ensino do direito internacional focando nos docentes e em sua prática em instituições brasileiras ${ }^{5}$.

A pesquisa, feita entre 2014 e 2015 , teve por foco o ensino da disciplina de direito internacional no curso de graduação em direito em quinze instituições brasileiras ${ }^{6}$ e adotou a perspectiva dos docentes ${ }^{7}$ de cada uma dessas instituições, através de uma abordagem multimétodos ${ }^{8}$. No total, 45 professores participaram de entrevistas e responderam a surveys, que conjuntamente abordaram os seguintes aspectos: (1) trajetória acadêmica e profissional do docente e seu envolvimento com o direito internacional; (2) relação entre o

4 A pesquisa "A prática do ensino do direito internacional na perspectiva dos docentes", foi feita entre 2014 e 2015, por uma parceria entre o Núcleo de Direito Global e Desenvolvimento e o Núcleo de Metodologia de Ensino da FGV Direito SP, em equipe constituída por Adriane Sanctis de Brito, Camila Souza Alves, Carolina Dalla Pacce, Guilherme Forma Klafke, Julia Trindade de Sá, Luciana de Oliveira Ramos, Thiago São Marcos Nogueira, Ramon Alberto dos Santos e coordenada por Salem Hikmat Nasser e por José Garcez Ghirardi. A pesquisa recebeu apoio do Auxílio Regular (Processo n. 2014/00315-4) da Fundação de Amparo à Pesquisa do Estado de São Paulo (Fapesp). As opiniões, hipóteses e conclusões ou recomendações expressas neste material são de responsabilidade dos autores e não necessariamente refletem a visão da FAPESP.

5 A investigação partiu da premissa de que os profissionais envolvidos com o direito internacional tomam parte da construção da teoria, assim como a teoria constitui sua prática profissional. Sobre isso. Ver Koskenniemi, M. Between commitment and Cynism: Outline for a Theory of International Law as Practice. In KoskenniemI, M. The Politics of International Law, Portland, Hart, 2011, 271-293; Bourdieu, P. Homo academicus, California, Stanford University Press, 1988; Bourdieu, P., Passeron, J-C., De Saint Martin, M. Academic discourse: Linguistic misunderstanding and professorial power, California, Stanford University Press, 1996.

6 FGV-SP - São Paulo/SP; UERJ - Rio de Janeiro/RJ; UfJF - Juiz de Fora/MG; UFMG - Belo Horizonte/ MG; UfPE - Recife/PE; UfPEL - Pelotas/RS; UFPR - Curitiba/PR; ufRGS -Porto Alegre/RS; UfRN - Natal e Caicó/RN; ufsm - Santa Maria/RS; Ufv - Viçosa/MG; UnB - Brasília/DF; Unesp Franca/SP; Unip - São Paulo/SP; USP - São Paulo/SP. A lista de resultados de aprovação da Ordem dos Advogados do Brasil, o Ranking Universitário Folha (RUF) e o Conceito Preliminar de Curso (CPC) do Inep foram combinados para a seleção das quinze instituições mais bem avaliadas. Essa listagem corresponde, portanto, às quinze instituições com maior número total de aparições na combinação de tais rankings nas versões disponíveis em 2014. Os três rankings representam diferentes perspectivas de avaliação, já que focam respectivamente na capacidade de aprovação dos alunos no exame de admissão para a carreira advocatícia, a recepção dos egressos no mercado de trabalho; e qualidade de curso e infraestrutura da instituição. Caso houvesse avaliação específica de ensino do direito internacional, ela seria a escolhida para a seleção da amostra, mas como não existe esse tipo de avaliação no país, foram escolhidas avaliações que lidam separadamente com as instituições de ensino do direito.

7 Optamos por resguardar o caráter anônimo de todas as manifestações, com o que concordaram todos os entrevistados. Por isso, as falas citadas neste artigo, ainda que reproduzam fielmente as transcrições de entrevistas, não serão identificadas quanto a seus autores.

8 Entrevistas semiestruturadas buscaram captar e examinar a visão dos docentes sobre sua prática de ensino e suas avaliações sobre ela; a aplicação de questionário aferiu dados objetivos sobre o contexto de trabalho docente; para informar a leitura dos resultados aferidos pelos métodos anteriores, foi feita análise documental tanto dos currículos dos docentes na plataforma integrada nacional Lattes CNPq, quanto dos programas de disciplina enviados pelos docentes ou disponíveis online. 
docente e a disciplina; (3) relação entre docente e seus métodos de ensino; (4) desafios enfrentados pelos docentes para a prática de ensino do direito internacional.

Essa investigação rendeu um material bastante rico e complexo, irredutível a uma conclusão objetiva sobre quais atitudes de ensino predominam entre os professores brasileiros, ou mesmo à construção de "tipos" de professores de direito internacional. Para fazer jus à diversidade de perspectivas que encontramos, mostraremos aqui algumas tendências, através das concordâncias e discordâncias desses docentes sobre temas comuns.

Nosso intuito com essa exposição é provocar debates e instigar novas ideias de pesquisa que aprofundem a reflexão sobre as funções da disciplina e o papel do professor em sua prática profissional. Sem dúvida, ainda há muito terreno a percorrer para detalhar o conhecimento da prática docente tanto no Brasil quanto na América Latina, seja para entender melhor os problemas brasileiros, seja para estabelecer os pontos que podem constituir um diálogo latino-americano acerca dos desafios do ensino do direito internacional.

\section{QUEM SÃO OS PROFESSORES: PERFIL DEMOGRÁFICO E FORMAÇÃO}

Ao estabelecerem relações entre sua trajetória e os modos como veem sua prática docente, os entrevistados fizeram muitas menções a memórias de sua própria formação em direito, na graduação ou na pós-graduação. Menções específicas a disciplinas de direito internacional, contudo, foram raras. No Brasil, apenas em 1994 (com implementação nos anos posteriores) passou a ser obrigatória a inclusão de disciplinas de Direito Internacional Público e Direito Internacional Privado no currículo básico dos cursos jurídicos ${ }^{9}$. Ainda que não haja levantamento disponível de quais cursos continham a disciplina de forma optativa, o fato é que cerca de metade dos entrevistados passaram pelo curso de graduação antes da obrigatoriedade, e alguns indicaram expressamente nas entrevistas que não tiveram a matéria durante a graduação.

Entre os 45 entrevistados, 40 possuem doutorado e 15 realizaram pós-doutorado. A titulação da amostra trabalhada mostrou-se superior à média dos docentes nos cursos de direito no Brasil, em que apenas $25 \%$ detêm o título de doutor. A diferença persiste mesmo em relação aos docentes dos cursos públicos de direito no país, em que a média de doutores é de $35 \%{ }^{10}$. Os docentes se formaram, nos níveis de graduação e pós-graduação, em diversas

9 Brasil. Ministério da Educação, Portaria n. 1886, de 30 de dezembro de 1994.

10 Núcleo de Metodologia de Ensino. Detalhamento regional da área de direito, Observatório do Ensino do Direito. V. 1. N. 1, outubro de 2013. Consulta em 25 de outubro de 2016 em: http://direitosp.fgv.br/sites/direitosp.fgv.br/files/arquivos/relatorio_oed_out_2013quem_e_o_professor_de_direito_no_brasil.pdf 
instituições. No nível de doutorado, a Universidade de São Paulo se destaca por ter formado cerca de um quarto dos entrevistados.

Em um terço dos casos os docentes atuam profissionalmente em um estado diferente do local onde cursaram a graduação, evidenciando um grau razoável de mobilidade. Já em relação à pós-graduação esse índice aumenta para mais da metade dos professores atuando em locais diferentes daqueles em que obtiveram seu mestrado ou seu doutorado. Todos os docentes com título de pós-doutorado obtiveram-no no exterior. Dos 45 docentes, 26 tiveram algum título obtido no exterior. Todos esses títulos, com exceção de um, foram cursados em países europeus ou nos Estados Unidos.

Dos 45 entrevistados, 37 declaram em seus currículos que dominam três (15), quatro (11) ou cinco (11) idiomas estrangeiros. Todos os entrevistados declararam dominar o inglês, seguidos de 42 que dominam o espanhol, 39 o francês, 19 o italiano, 16 o alemão, e 2 o japonês. Metade indica em seu currículo alguma atuação profissional fora do país durante a carreira.

A média de idade dos respondentes é de 47,3 anos, com um tempo médio de experiência docente de 13 anos e três meses. Sobre a forma de dedicação atual, a amostra apresentava mais de metade dos docentes atuando em regime de exclusividade, enquanto a média nacional dos professores dos cursos de direito é de um terço ${ }^{11}$. Cada um dos docentes entrevistados ministra de duas a três disciplinas (de graduação e/ou pós-graduação) por semestre.

\section{PERFIL DO ENSINO ATUAL: AULAS EXPOSITIVAS, INTERESSE DOS ALUNOS E CONTEÚDO BÁSICO}

A quase totalidade dos entrevistados indicou que utiliza o modelo magister dicit, de exposição oral da matéria aos alunos. Um quarto deles combina esse método com outros. Há diferença entre os métodos empregados nas disciplinas obrigatórias e nas disciplinas optativas, segundo os relatos, porque que nas últimas é possível fazer debates. Somente dois professores indicaram que utilizam o diálogo como método em sala de aula independentemente da natureza da disciplina.

A escolha de método parece estar relacionada com o posicionamento dos docentes tanto em relação a sua responsabilidade de despertar interesse nos alunos, quanto sobre sua relação com o conteúdo da disciplina.

Encontramos grandes divergências nas visões sobre o papel dos docentes na determinação do interesse ou desinteresse dos alunos pelo direito internacional. "Bom, se o aluno não está interessado, a única coisa que eu posso fazer é sentir muito", comenta uma docente. Na sua visão, seu papel é estar absolutamente disponível aos alunos interessados, "[p]orque muitas vezes a gente não pode imputar interesse ou não interesse, como uma relação com

Detalhamento regional, cit. 
culpa do professor, porque às vezes o desinteresse é por outras questões, às vezes pessoalíssimas".

Outra docente indica que o interesse deve partir tanto do aluno quanto do professor: "Eu tenho no escritório um menino universitário [...] que, olha, é impressionante, ele veio sem saber nada [...], e hoje sabe tanto quanto eu. Por quê? Porque foi atrás, né”. Mas também cabe ao professor despertar esse interesse, segundo ela: "aqui a gente tem que ir atrás também, tem que deixar o aluno mais instigado".

Outros professores enfatizam que é o docente o sujeito capaz de despertar o interesse nos alunos. Um docente explica: "realmente eu acho que o professor é muito importante, né, para despertar o interesse do aluno na matéria, para encorajá-lo também, incentivá-lo". Outra docente relata que busca sempre aumentar o número de alunos interessados na sala de aula, "a gente tenta chamá-los de alguma forma".

Em algumas falas, ainda, a escolha pela aula expositiva é relacionada diretamente ao interesse dos alunos. Na fala a seguir, o docente aponta essa relação situando sua experiência docente em direito internacional nos últimos anos do curso, como é mais comum ocorrer em instituições brasileiras: "[u] $m$ aluno de fim de faculdade tem um pouco de dificuldade com aula participativa. Ele associa a aula participativa [...] como se eu tivesse matando aula, ou enrolando. O aluno prefere aula expositiva". Outro docente demonstra a crença de que a forma expositiva é a mais correta como forma de interação entre o aluno e o professor em sala de aula: "Eu acho que o professor, o aluno aqui ele [es]tá em busca de informação, sabe, então eu acho que o estudo dirigido é uma coisa importantíssima, ótima, mas fazer isso fora de sala de aula, sabe, com um grupo de estudos, tá, ou um sábado". Sobre o uso de estudos dirigidos ou debates na sala de aula, ele acredita que "é você já querer enrolar um pouco, não [es]tá a fim de dar aula. Você [es]tá com a garganta ruim, e daí em diante".

Ao serem perguntados por survey sobre pré-determinações institucionais de conteúdos e programas, grande parte dos respondentes indicou que havia diretrizes de conteúdo para cada disciplina e uma minoria indicou que havia diretrizes de conteúdo para cada uma das aulas. Contudo, durante as entrevistas, os condicionamentos institucionais não emergiram como fator relevante para as escolhas de conteúdo. Pelo contrário, muitos dos professores se referiam às diretrizes como meras sugestões, ou indicações que poderiam descumprir diante da liberdade de cátedra. Alguns inclusive se referem a uma "tradição" que se sobrepõe à importância de diretrizes: "teve a influência, não da instituição como se ela dispusesse de um órgão central formulador de programas e que fossem sugeridos ou impostos aos professores, mas a influência do passado da instituição, que mereceu uma continuidade".

Ainda que houvesse certa divergência sobre o grau de responsabilidade dos professores em despertar o interesse dos alunos, ficou bem definido 
nas falas dos professores um senso de responsabilidade por apresentar o conteúdo da disciplina. Quando perguntados em entrevista sobre como escolhiam o que deveria ser ensinado ao aluno, grande parte dos professores fez alguma referência ao que chamavam de "conteúdo básico", "conceitos mínimos", "conceitos indispensáveis", "conceitos fundamentais", "conceitos incontornáveis", "alicerces incontornáveis" ou "que tem que ser dado em qualquer circunstância". Um exemplo claro está na fala de um docente: "a indagação que eu faço é, o que é que ela deveria saber. Visto que ela nunca estudou Direito Internacional Público, o que ela deveria saber sobre Direito Internacional Público?"12.

Alguns entrevistados indicavam quais os temas que representavam esses conteúdos, seja fazendo referência a manuais da disciplina, seja indicando um consenso do campo sobre como os estudantes deveriam ser "alfabetizados" em direito internacional. Essa última noção fica bastante clara nesta fala: "sujeitos de Direito Internacional, o Estado, seu território, população, águas territoriais, isso aí não tem jeito, isso aí, isso é o bê-á-bá. Então isso você tem que dar".

Já em referência aos materiais didáticos, este docente comentou: "você tem o programa da disciplina que tá em todo e qualquer índice de qualquer manual em qualquer lugar do mundo, [...] tem lá tratado, costume, sociedade internacional, ou seja, não tem como fugir, o aluno tem que saber o básico pra ele conseguir ir além".

Alguns professores inclusive relacionaram a importância desses conteúdos básicos com a atuação profissional: "fontes, direito dos tratados [...]. Você tem que dar, porque, me parece, qualquer âmbito do Direito Internacional em que você vai atuar, esses são conceitos operativos essenciais". Outros colocam os conteúdos básicos como um primeiro passo essencial: "bem apreendidos esses conceitos fundamentais, pode-se fazer uma reflexão crítica sobre essa questão". Outros justificam a prioridade por conceitos básicos com base na diferença de escopo entre a graduação e a pós-graduação: "na graduação é um pouquinho mais clássico, de temas mais gerais, então temas citados na maioria dos livros, temas mais clássicos de Direito Internacional".

Via de regra os conteúdos básicos têm prioridade nas escolhas de conteúdo a ser passado aos alunos, mesmo que alguns professores declarem que adicionam alguns temas de interesse próprio, de interesse dos alunos ou temas que acreditam que despertarão maior interesse pela disciplina.

O mesmo "conteúdo básico", por outro lado, apareceu como limitador da relação entre ensino e pesquisa, ou mesmo da interdisciplinaridade. Como o foco da nossa pesquisa era a prática do professor dentro da sala de aula, em

12 Esses "conhecimentos compartilhados" normalmente eram separados entre temas diferentes, no caso de Direito Internacional Público ou Direito Internacional Privado. Contudo, como essa pesquisa não enfocou a separação disciplinar, esse ponto não será abordado aqui. 
uma esfera disciplinar, os professores não eram explicitamente estimulados a falar sobre sua atuação em grupos de estudo, orientações, ou projetos de pesquisa que não se relacionavam com essa forma de ensino. Contudo, cerca de metade dos entrevistados fez menção a práticas de pesquisa. Grande parte das menções se referiam ao conteúdo do direito internacional ensinado ou à forma como isso era feito. Dentre as variações, estiveram indicações de que os conteúdos aprendidos em experiências de pesquisa eram repassados na sala de aula (6); a interdisciplinaridade em experiências de pesquisa se refletia nas escolhas de materiais/conteúdos (2); as preocupações de pesquisa se refletiam na escolha do conteúdo das aulas (7); a escolha da bibliografia da disciplina se relacionava ao modo como o docente estudou determinada matéria (4).

Embora três quartos dos docentes respondentes do survey tenham indicado participar de atividades de grupos de pesquisa, treinamento para simulações internacionais e outros espaços de pesquisa, apenas uma minoria de 5 deles indicaram uma integração com as atividades em sala de aula. "Então, além das minhas aulas, eu acabei o quê? Associando as disciplinas a determinados grupos de estudos que foram essenciais", comenta um professor. Nessa linha, uma docente indica que a integração tem sido feita em conjunto com outros professores, de forma interdisciplinar: "é uma tendência que começa a mudar a partir da clínica de Direitos Humanos e a partir da reformulação do Núcleo de Prática Jurídica em projetos, e nessa articulação com outros professores de várias outras disciplinas".

Ao serem perguntados sobre sua visão acerca da interdisciplinaridade, grande parte dos professores disse sim julgar importante a inserção de visões não-jurídicas à sua disciplina, às vezes inclusive convidando docentes de outras áreas para ministrar aulas como convidados ou indicando que os alunos se aprofundem em temas de economia, relações internacionais ou ciências sociais por meio de leituras extras. Essas iniciativas não constituíam o cerne das escolhas de conteúdo dos professores, entretanto, e raramente aparecem como resultado de um arranjo institucional de ensino. Pelo contrário, o local do curso e a falta de espaços de troca são indicados como impeditivos para uma interação que os docentes declaram valorizar.

Além disso, mais uma vez o "conteúdo básico" aparece na fala de muitos entrevistados como um obstáculo à inovação ou à inserção de influências de pesquisa e da interdisciplinaridade na medida em que os docentes gostariam. Eles se referem tanto à inserção de matérias diferentes das normalmente abordadas nas disciplinas quanto à modificação da metodologia de ensino. Uma docente comenta: "se a gente não tomar cuidado a gente não fecha esse conteúdo programático. Então às vezes a gente não tem oportunidade de fazer algumas coisas diferentes". Isso ocorre especialmente nas disciplinas obrigatórias: "então as disciplinas obrigatórias, porque têm uma ementa pré-definida, têm um conteúdo mínimo pré-definido que eu preciso lecionar. 
Então fica pronto nesse sentido, fica mais difícil de você trazer novidades ou indagações mais profundas".

\section{OS DESAFIOS: ENTRE PROBLEMAS DA DISCIPLINA E A INFRAESTRUTURA INSTITUCIONAL}

Quando falavam tanto da estratégia de suas escolhas de conteúdo e metodologia, ou mesmo diretamente sobre os desafios que enfrentavam em sua prática docente, o elemento que mais apareceu em destaque foi o problema do tratamento de "segunda categoria" normalmente dado ao direito internacional. Ao expressarem de diferentes formas uma certa desvalorização da disciplina, era comum os entrevistados partirem da comparação com outras disciplinas do currículo dos cursos de direito.

Há unanimidade entre os professores na constatação de que os alunos normalmente resistem ao direito internacional. Os entrevistados divergem sobre quão difícil é lidar com essa questão, o que se relaciona com enxergarem diferentes causas do problema.

Um entrevistado comentou que sua primeira preocupação ao assumir a posição de docência em sua instituição foi de que o direito internacional "fosse respeitado enquanto uma disciplina jurídica, e não compreendido como uma disciplina de Geografia, de Conhecimentos Gerais". Na mesma linha, outro entrevistado explica que há um "preconceito com o direito internacional", a ideia de que é um sistema menos efetivo, pela "inexistência de um órgão coercitivo no plano internacional". Segundo ele, o direito interno é cultuado nas faculdades de direito. "Então isso ainda é um desafio, [...], uma forma diferente de compreensão do Direito [...], essa forma mais cooperativa que o Direito Internacional tem, não subordinativa".

Outro entrevistado enxerga o mesmo desafio, que chama de "célebre problema da sanção no Direito Internacional Público". Isso vem "da tendência que todo estudante de Direito tem de identificar o Direito no âmbito jurídico nacional, mas é um reflexo que todo estudante de Direito tem, [...] inclusive eu tinha, então, e o que é natural". Ele acredita ser um obstáculo plenamente superável, ainda que o professor de direito internacional seja-citando um autor inglês- "o único professor de Direito que tem que explicar [...] por que é jurídica essa disciplina".

Esse ponto deve ser trabalhado "em todas as disciplinas", para que os alunos sejam capazes de enxergar "a dinâmica do Direito Internacional", adiciona outro entrevistado. "É esclarecer a relação que se estabelece entre Direito Interno e Direito Internacional". Segundo ele, "o nosso ensino de Direito está muito fundado no Direito do país [...] é fácil ver os vários outros ramos: Direito Tributário, Societário, Administrativo, Civil...”. Completa: "É difícil você enxergar o Direito Internacional como parte desse Direito Interno e entender essa relação que se estabelece". Para ele, a chave de 
compreensão está em se esclarecer se "há uma hierarquia, não há, Direito Interno compreende o Direito Internacional ou não, [...], quais são os efeitos que o Direito Internacional tem sobre o Direito Interno".

Alguns entrevistados ligam essa desvantagem comparativa do direito internacional em relação a outras disciplinas com uma ideia de aparente inutilidade da disciplina. Um entrevistado, como vários outros, traz uma expressão bastante recorrente nas instituições brasileiras para referência ao direito internacional. Quando era perguntado sobre qual a sua área de maior interesse durante a graduação, respondia que era o direito internacional e tinha como reação algo como "Isso é uma perfumaria jurídica! Bom mesmo é Processo Civil". O entrevistado completa que "desde que eu ingressei na faculdade de Direito eu escuto isso, então eu não sei até que ponto isso é uma dificuldade atual". Outro explica que "a grande percepção acadêmica dos estudantes é no sentido de que o Direito Internacional não serve para nada".

Outro elemento que apareceu com frequência na fala dos entrevistados foi a falta de concretude aparente do direito internacional, que se relaciona intimamente com essa aparência de futilidade da disciplina. O elemento da concretude é trazido inclusive separadamente da questão da comparação com outras disciplinas. Um entrevistado indica: "uma dificuldade que provavelmente todos os seus entrevistados devem ter exposto, é $[\ldots]$ o pequeno appeal que o Direito Internacional tem". Isso se deve à visão, segundo ele corroborada pela prática dos internacionalistas, "de que o Direito Internacional [...] é muito distante da realidade das pessoas". E é isso o que faz os alunos acreditarem na falta de uma importância prática da disciplina. Outro entrevistado, também se referindo a esse fator, indica que " $\mathrm{t}]$ alvez falte nos nossos professores, e aí eu me incluo, mais vinculação com a prática. Então, quer dizer, de que forma eu uso esse tratado, essa convenção? Então de que forma $[\ldots]$ podem entrar em um caso concreto?".

Mas essa falta de concretude não é apenas ligada à matéria ensinada ou mesmo à forma como é ensinada pela sala de aula. Isso também se relaciona ao local de vivência dos alunos: Aí vai depender um pouco [...] de onde você está também geograficamente. Eu imagino que em alguns lugares é mais fácil lecionar o Direito Internacional do que em outros". Uma docente relata que normalmente diz aos alunos: "olha, o mundo não é o Rio de Janeiro, o mundo não é o Brasil, o mundo não é a América Latina, [...] não pode só pensar que vocês vão atuar aqui".

Na cidade onde leciona, comenta outro entrevistado, há um "distanciamento da teoria e prática em Direito Internacional", porque "apesar de ser uma capital, o estado não tem. Vamos dizer assim, uma importância econômica como teve no passado". Isso leva a uma "dificuldade de conhecer, na prática, aquilo que eu estou falando na teoria". Outro relato é bastante semelhante, ligando a falta de conexão com a realidade dos alunos: "pelo fato de estarmos numa região, de um certo modo, geograficamente mais afastada ou mais 
remotamente ligada ou interligada para com outras dimensões geopolíticas consideradas em nível mundial".

O mesmo entrevistado aponta para a provável diferença nesse aspecto entre diversas regiões do país: "o nível de atividade empresarial e de importações e exportações do nordeste [...] não é tão significativo quanto [...] em outras regiões do Brasil, como o sudeste e a sul". Por isso, explica: "no sul parece mais pujante a presença das disciplinas jus-internacionalistas, na medida em que se presume que a interatividade ou mesmo os contatos fronteiriços permeassem de um certo modo essa consciência acadêmica, quer docente, quer discente". O entrevistado ainda pondera: "É sabido que as conexões não se estabelecem hoje mais tanto do ponto de vista físico, mas também [...] através de meios mais sofisticados, os quais transpõem fronteiras geopolíticas e geofísicas". Isso não diminui as distâncias entre seus alunos e o direito internacional, contudo, já que "o nordeste também não está apenas isolado ou mais remotamente ligado à sociedade internacional por limitações ou por distanciamentos geofísicos ou geopolíticos, mas também por razões, na minha opinião, econômicas".

Outra linha de diagnóstico dos professores é de um certo elitismo da área do direito internacional em relação às demais. Segundo esses relatos, "é uma área que é elitista porque ela exige uma bagagem cultural, ela exige conhecimento de línguas, ela exige que você tenha disponibilidade de viajar, de fazer concursos", o que depende de recursos financeiros. A consequência que esse entrevistado percebe é que "embora exista gente sobrando na área jurídica, no Internacional, comparativamente, falta gente qualificada ainda".

Um dos elementos que mais foi repetido entre os docentes foi o problema de que muito do material que deveria ser utilizado para o ensino existe apenas em idiomas estrangeiros. Pelo menos um terço dos entrevistados relatou alguma dificuldade em depender de materiais em outros idiomas (entre livros didáticos, jurisprudência ou artigos acadêmicos) para passar o conteúdo ideal aos alunos. Um entrevistado comenta: "então isso eu acho que é o maior desafio que nós temos hoje no Direito Internacional, no ensino do Direito Internacional, é ter fontes primárias em português e. Vamos dizer, bibliografia de primeira mão sobre os problemas internacionais. Nós não temos". Outro acredita que a situação melhorou nos últimos anos, mas relata: "quando eu comecei, em 2000, nós tínhamos ainda um número bastante restrito de obras, e até de possibilidades em língua portuguesa, e muitos dos meus alunos no interior não tinham domínio de língua inglesa pra leitura de um texto".

Outros entrevistados ainda relacionaram o conhecimento de idiomas com a situação financeira dos alunos, dizendo que embora seja desejável a leitura de materiais em seus idiomas originais, isso acaba excluindo os alunos que não tiveram oportunidade de desenvolver o conhecimento necessário nos anos de ensino básico, especialmente aqueles que ingressaram na universidade por meio de cotas. Outro entrevistado indica que, além do custo financeiro 
de se dedicar ao direito internacional ser maior, também depende de maior investimento pessoal: "você tem que gostar de estudar, porque se você não gostar você não pode ir pra Internacional. Você vai fazer qualquer outra coisa no Direto. Internacional não pode. A formação é muito longa".

Uma entrevistada diverge diretamente de visões na linha anterior, dizendo que a área não é necessariamente elitista, dependente de conhecimentos em idiomas estrangeiros ou de um eruditismo aristocrata. Pelo contrário, o direito internacional "[é] muito popular, muito, como qualquer outro ramo do Direito". Para ela, "a desmistificação é muito importante [...]. Até porque geralmente o professor de Direito Internacional vem com uma pompa, uma circunstância [...] fala inglês, fala francês, "viajei pra França"'. Ela completa: "Não, isso não quer dizer nada. Você tem que tornar o Direito Internacional mais popular".

Tanto a questão da concretude quanto aquela de uma possível "inferioridade" em relação a certas disciplinas parece contribuir para um desprestígio do direito internacional, na visão de grande parte dos entrevistados. Contudo, esse desprestígio também aparece independentemente dos dois primeiros elementos. Sinal do desprestígio, segundo alguns relatos, é a posição reservada para o direito internacional na grade curricular dos cursos de direito.

Por alguns anos, no Brasil, como já comentamos, a regulação nacional permitia a inclusão do direito internacional nos currículos dos cursos de direito como matéria meramente optativa. Na opinião de um entrevistado, a tendência atual de sua instituição buscar diminuir a carga horária da disciplina traz o risco de reproduzir o problema, hoje explícito, da geração que não teve a matéria em grade obrigatória: "você vê gente que se formou pelo Brasil afora, no tempo em que era optativa [...], e vai depois para Tribunais Superiores e às vezes fala absurdos, porque faltou o Direito Internacional na graduação, e não estudou depois".

Um entrevistado comenta que o excesso de disciplinas na carga horária semestral dos alunos impede que eles se preparem apropriadamente para as aulas: "[e]ntão o sistema como é feito, curricular, ele inviabiliza essa preparação". A posição da disciplina na grade também interfere no interesse geral do aluno, na visão de outro entrevistado: "se ele é ministrado no fim do curso, o aluno [es] tá interessado na conclusão do curso, no exame de Ordem [dos Advogados do Brasil], no trabalho de conclusão de curso, e em outras coisas, na formatura, etc.". "Então a tendência dos professores de quinto ano é trabalhar com o Direito Internacional cobrado nos concursos", completa.

Ensinar direito internacional em outros anos, na sua visão, permite outras abordagens: "no terceiro ano ele trabalha isso conseguindo aliar a cultura jurídica, a teoria do estado e a essência política, com um aluno mais maduro; [...] no começo do curso [...], tem um aluno um pouco mais imaturo, um aluno que ainda precisa de uma base formativa maior". Outro entrevistado concorda com essa diferença: "lidar com aluno que está no final do curso é 
sempre mais difícil. [...] O aluno de início de curso, embora ele ainda não tenha uma formação jurídica, ele tem um interesse. Via de regra, um interesse muito maior, uma abertura muito maior". Outra professora adiciona: "você vai dar uma aula enfadonha pra esse aluno que já está preocupado com o que fazer depois da faculdade".

Um outro fator destacado foi a diferença de se ensinar uma disciplina obrigatória ou uma disciplina optativa. Os docentes apontam que há um filtro de alunos com interesse pela matéria nas optativas. Por isso os alunos tendem a se dedicar mais à preparação para as aulas, à participação e a uma melhor recepção de temas mais complexos. Nas optativas, os docentes têm mais liberdade de escolha de métodos, justamente pela maior dedicação dos alunos ou pelo número de participantes ser menor. "Então na optativa eu vejo que eles se dedicam mais à leitura, então é possível a gente fazer mais aulas-seminários, né, com maior participação deles. Na obrigatória, efetivamente, eu acho que fica já mais complicado". Outro entrevistado concorda: "Assim, sem dúvida, [...], nas disciplinas eletivas você consegue burlar esse sistema. E é ótimo porque aí você fica com os melhores alunos, só com os mais interessados". Outros docentes adicionam outros elementos de diferença, ligados à seleção dos alunos: "nas disciplinas optativas eu conto com alunos mais interessados, [...], assim, é condição, ou pelo menos eu arrolo como condição para participação, o conhecimento de língua inglesa".

Outros docentes relacionam o desprestígio da disciplina com a falta de cobrança da matéria ou a forma como isso é feito em provas de ingresso a carreiras jurídicas. Um entrevistado traz o exemplo da advocacia, onde "há escritórios especializados em áreas públicas, privadas, comerciais e [de] investimentos dentro do Direito Internacional, mas que não são respaldados pela própria organização que representa o interesse dos advogados, a OAB". A Ordem dos Advogados do Brasil é a entidade máxima de representação dos advogados no país, responsável pela aplicação de exame que condiciona a permissão para advogar em território nacional. Atualmente, a primeira fase do exame contém apenas duas questões que abordam matérias de direito internacional de um total de oitenta questões. Na segunda fase, os candidatos devem escolher responder questões dissertativas dentre as áreas de direito constitucional, administrativo, civil, penal, empresarial, trabalho ou tributário. Outro entrevistado comenta sobre o mesmo ponto: "muitas vezes eu vejo que eles [os alunos] olham os exames de Ordem e vão procurar as perguntas que tem, que tocam nos sistemas internacionais. E então há uma espécie de utilitarismo [...] com relação à disciplina".

O mesmo entrevistado complementa que essa preocupação se estende aos concursos para outras carreiras, como magistratura, defensoria pública e ministério público. Anda que tais concursos venham cada vez mais incluindo matérias de direito internacional em seus exames de ingresso, completa o entrevistado, é necessário "fazer com que os concursos deem importância 
ao Direito Internacional, mas não com perguntas de armadilha, mas sim com perguntas elaboradas para testar o verdadeiro conhecimento deles".

A infraestrutura também tem papel decisivo para dificultar o ensino do direito internacional. Algumas das falas levam a crer que esses problemas não se relacionam diretamente à disciplina de direito internacional, mas ao curso de direito como um todo ou mesmo a toda a instituição de ensino. "Eu vejo que a gente tem um problema sério de infraestrutura na universidade, muita coisa faltando na universidade, coisas que eu acho que não deveriam faltar e faltam, na biblioteca.. papel.. não tem dinheiro pra trazer palestrante", comenta uma docente.

Ela explica que não vê esses problemas como específicos do direito internacional, mas que constituem impedimentos para a melhoria do ensino no dia-a-dia. Outros entrevistados mencionam a indisponibilidade de obras de consulta nas bibliotecas, ou falta de acesso a bases de dados, o que prejudica especialmente a atualização do conteúdo das disciplinas e o diálogo com a produção internacional.

\section{CONSIDERAÇÕES FINAIS}

Esboçamos aqui uma forma de olhar para o quadro geral de como é a prática e quais os desafios do ensino do direito internacional no Brasil. Nossa escolha foi por explorar a narrativa dos docentes (ou de alguns deles) sobre sua própria atuação e os problemas que enfrentam. Mas é claro que esse é apenas um primeiro passo para entender a realidade do ensino do direito internacional, no Brasil ou em outros contextos.

Para qualquer descrição que tenha função propositiva, importam também as visões dos outros atores que participam do processo de ensino e, claro, a estrutura em que se situam. Por isso, seria essencial olhar tanto para as perspetivas das instituições de ensino quanto dos alunos, e perguntar quem são, quais seus projetos, quais seus desafios. E observar regulações de ensino superior, políticas de ensino, ou mesmo as condições sociais nacionais, que constituem fatores essenciais para entender um quadro geral de ensino.

Em nossa pesquisa escolhemos direcionar a investigação para a sala de aula, dentro de um paradigma de ensino disciplinar, que não necessariamente corresponde à melhor forma como alunos adquirem habilidades ou conhecimentos em um ambiente universitário. Outros ambientes não disciplinares como grupos de estudos, clínicas jurídicas, coaching para competições internacionais, pesquisas em iniciação científica, entre outros formatos, podem inclusive oferecer muito mais para responder ao que se escolhe como os objetivos de uma universidade.

Por isso os resultados dessa pesquisa devem ser vistos com olhos humildes de iniciantes, porque há tanto para buscarmos saber para fundamentar descrições que retratem a realidade do ensino do direito internacional. Nossa 
intenção é de que alguns dos elementos trazidos aqui incitem tanto outras pesquisas descritivas mais detalhadas, quanto pontos de diálogo em experiências comparadas. Continuar essa busca é o que nos leva a refletir sobre os objetivos do ensino do direito internacional e as escolhas do quê ensinar e como, em um contexto nacional ou latino-americano.

\section{REFERÊNCIAS}

American Society of International Law. (2004). Workshop on the Yeaching of International Law. Washington D.C.

Berman, P. S. (2005). Towards a Cosmopolitan Vision of Conflict of Laws: Redefining Governmental Interests in a Global Era. University of Pennsylvania Law Review. V. 153. N. 6, 1819-1882.

Bourdieu, P. (1988). Homo academicus. California: Stanford University Press.

Bourdieu, P.; Passeron, J-C. y De Saint Martin, M. (1996). Academic discourse: Linguistic misunderstanding and professorial power. California, Stanford University Press.

Brasil. Ministério da Educação (1994). Portaria N. 1886, 30 de dezembro.

Brito, A. Sanctis de e Klafke, G. Forma. O ensino de Direito Global entre o velho aluno e o novo professor. In Badin, M. Ratton Sanchez, Brito, A. Sanctis de e Ventura, D. DE Freitas Lima. Direito global e suas alternativas metodológicas: primeiros passos. São Paulo: Acadêmica Livre, 2016, 177-205.

European Society of International Law. International Law as a Profession, 23-15 de maio de 2013. Consultado em 10 de maio de 2016 em: http://www.esil2013.nl/

Folha de São Paulo. Ranking Universitário Folha, 2013. Consulta em 23 de outubro de 2016 em: http://ruf.folha.uol.com.br/2013/

Ghirardi, J. Garcez. (2012). O instante do encontro: questões fundamentais para o ensino jurídico. São Paulo: Fundação Getulio Vargas.

Hikmat NASSER, S. (2009). Imaginação e territoralidade: o ensino do direito internacional. In Ghirardi, J. Garcez e Vanzella, R. Domingos Faiardo (org.). Ensino jurídico participativo: construção de programas e experiências didáticas. São Paulo: Saraiva, 129-138.

Hikmat Nasser, S. (2016). Uma dança de três: Direito Internacional, Relações Internacionais e Direito Comparado. In Badin, M. Ratton Sanchez, Brito, A. Sanctis de e Ventura, D. DE Freitas Lima. Direito global e suas alternativas metodológicas: primeiros passos. São Paulo: Acadêmica Livre, 169-176.

Hoffmann, F. Teaching general public international law. In KAMMERHOFER, J. e D'AsPrEMONT, J. (eds). International legal positivism in a post-modern world. Cambridge: Cambridge University Press, 349-377.

Instituto Nacional de Estudos e Pesquisas Educacionais Anísio Teixeira. (2013). Conceito Preliminar de Curso. Consultado em 23 de outubro de 2016 em: http://portal.inep.gov. br/educacao-superior/indicadores/cpc 
International Law Association. Conference Reports, Teaching International Law Committee 1998-2010. Consultado em 10 de maio de 2016 em: http://www.ila-hq.org/en/ committees/index.cfm/cid/1009

KenNEDy, D. (1985). International Legal Education. Harvard International Law Journal, Cambridge. V. 26, 361-384.

Koskenniemi, M. (2011). Between commitment and Cynism: Outline for a Theory of International Law as Practice. In Koskenniemi, M. The Politics of International Law. Portland: Hart, 271-293.

Núcleo de Metodologia de Ensino. Detalhamento regional da área de direito. Observatório do Ensino do Direito. V. 1. N. 1, outubro de 2013. Consulta em 25 de outubro de 2016 em: http://direitosp.fgv.br/sites/direitosp.fgv.br/files/arquivos/relatorio_oed_ out_2013quem_e_o_professor_de_direito_no_brasil.pdf

Ordem dos Advogados do Brasil. x Exame de Ordem Unificado. Consultado em 28 de outubro de $2016 \mathrm{em:} \mathrm{http://www.oab.org.br/arquivos/desempenho-das-ies-1005403069.pdf}$

Santos, A. (2013). Carving Out Policy Autonomy for Developing Countries in the World Trade Organization: The Experience of Brazil. In TrubeK, D. et al. (eds.). Law and New Developmental State: The Brazilian Experience in Latin American Context. Cambridge: University of Cabridge, 167-245.

Schachter, O. (1997). The Invisible College of International Lawyers. Northwestern Law Review. V. 72. N. 2, 217-226.

Simpson, G. (1999). On the magic mountain: Teaching Public International Law. European Journal of International Law. V. 10. N. 1, 70-92.

Société Française pour le Droit International. (1997). Enseignement du Droit International Recherche et Pratique: Journée d'Études du 20 Janvier 1996 Organisée sous les Auspices de L'UNESCO, Paris, Editions A. Pedone.

Unger, R. Magabeira. Uma nova faculdade de direito no Brasil, 2001. Consultado em 13 de outubro de 2012 em: www.law.harvard.edu/unger/portuguese/docs/projetos6.doc 